\title{
A new high-frequency torsional rheometer for bituminous binders
}

\author{
L. D. Poulikakos ${ }^{1}$, M. B. Sayir ${ }^{2}$ and M. N. Partt ${ }^{1}$ \\ (1) Swiss Federal Laboratories for Materials Testing and Research, EMPA, Switzerland \\ (2) Swiss Federal Institute of Technology, ETH, Zürich, Switzerland
}

\begin{abstract}
When a rod is performing torsional vibrations at one of its resonance frequencies, any interaction with a viscoelastic medium will change both its resonance frequency and its damping characteristics. By measuring this change, modulus, phase angle, elastic and viscous constants of a bituminous binder can be obtained. The new High-Frequency Torsional resonance Rheometer (HFTR) developed at ETH Zuirich and presented in this study is based on this principle.

In comparison to prevailing rheometers, the HFTR is inexpensive and has various technical advantages. It can be embedded in the binder or placed on its surface and is suited for laboratory and field measurements. High frequencies in the 1 to $60 \mathrm{kHz}$ range allow the measurements to be unaffected by traffic induced low frequencies, which makes it ideal for field measurements. The HFTR can also be used for continuous monitoring of binder aging effects or as a portable fingerprinting tool for materials characterization in the laboratory. In addition, it allows continuous measurements during binder production.

This study focuses on the measurement technique using the HFTR for laboratory experiments involving conditioning of bitumen in a high temperature oven. Furthermore measurement uncertainties and practical examples are discussed.
\end{abstract}

\section{RÉSUMÉ}

Quand une tige entre en vibration torsionnelle à l'une de ses fréquences de résonance, toute interaction avec un matériau visco-élastique changera à la fois sa fréquence de résonance et ses caractéristiques d'amortissement. En mesurant cette variation, on peut obtenir le module, l'angle de phase, les constantes élastiques et visqueuses d'un liant bitumineux. Le nouveau Rhéomètre à résonance Torsionnelle Haute-Fréquence (HFTR en anglais) développé à l'ETH Zürich et présenté dans cette étude est basé sur ce principe.

En comparaison avec les rhéomètres actuellement prépondérants sur le marché, le HFTR est peu coûteux et a de nombreux avantages techniques. Il peut être plongé dans le liant ou placé sur sa surface et il est alors approprié aux mesures de laboratoire comme de terrain. La gamme de haute fréquences 1 à $60 \mathrm{kHz}$ a pour conséquence que les mesures ne sont pas affectées par les basses fréquences liées au trafic, ce qui le rend idéal pour les mesures de terrain. Le HFTR peut aussi être utilisé pour la surveillance continue des effets de vieillissement des liants ou être utilisé comme un outil portable réalisant des empreintes destinées à la caractérisation du matériou au laboratoire. En outre, il permet des mesures continues pendant la production de liants bitumineux.

Cette étude est centrée sur les mesures techniques utilisant le HFTR pour des expériences de laboratoire impliquant le conditionnement du bitume dans des fours à haute température. De plus les incertitudes de mesure et des exemples pratiques sont discutés.

\section{INTRODUCTION}

This still ongoing study is part of a research co-operation between EMPA Road Engineering/Sealing Components in Dïbendorf and the Institute of Mechanical Systems of ETH in Zurich focussing on the continuous monitoring of bituminous

Editorial Note:

Presented at the $6^{\text {th }}$ International RILEM Symposium on Performance Testing and Evaluation of Bituminous Materials (PTEBMM'03), held on 14th-16th April 2003, in Zurich, Switzerland, this paper was selected as an outstanding communication and peer-reviewed by the Scientific Committee of the Journal Materials and Structures.

Dr. Manfred N. Partl is a RILEM Fellow. He is the Chairman of RILEM TC 182-PEB 'Performance testing and evaluation of bituminous materials' and works at EMPA, Switzerland, a RILEM Titular Member. Dr. Partl was recently appointed as an expert in the RILEM Technical Activities Committee (TAC). 
binders exposed to various high temperatures. Standard oven and PAV aging tests were the basis for the choice of temperatures and conditioning times. A new High-Frequency Torsional resonance Rheometer (HFTR) developed at ETH is used to characterize the material investigated by EMPA. The overall aim of the project is to determine whether there are differences in aging characteristics between the selected binders that could be detected using the HFTR.

The aging process in a pavement consists of contimuous degradation and transformation of the components in bituminous binders under production and field conditions. This process is strongly related to the exposure of the binders to air and temperature and is therefore simulated by various accelerated aging laboratory tests like PAV, RTFOT and TFOT which involve exposing samples of thin binder films to heat, oxygen and pressure. After this treatment, these samples of thin films are usually mixed together in a homogenizing process and the resulting mixture is further used for material properties lesting. The HFTR method eliminates the influence of this mixing of the material and allows testing of the thin layer of bitumen mechanically in a much more undisturbed way. During the aging process in the oven, the new device allows monitoring of the influence of binder properties changes in the surface zone of the film that is directly exposed to heat and oxygen.

\section{THE HIGH-FREQUENCY TORSIONAL DYNAMIC RESONANCE RHEOMETER (HFTR)}

\subsection{System specifications and description}

The dynamic rheometer (material; 18-8 CrNi steel) consists of an outer tube rigidly joined at its end $\mathrm{E}$ to a cylindrical inner rod through an end plate (Fig. 1). The tube is free of loading along its lateral surface and aitached at one end $F$ to a thick plate PL of large diameter in comparison to the diameter of the tube. See Table 1 for the rheometer specifications.

Since the torsional rigidity of the plate is much larger than the tube, it acts as a decoupling mass enforcing a node of the torsional vibration mode in its immediate vicinity. The other

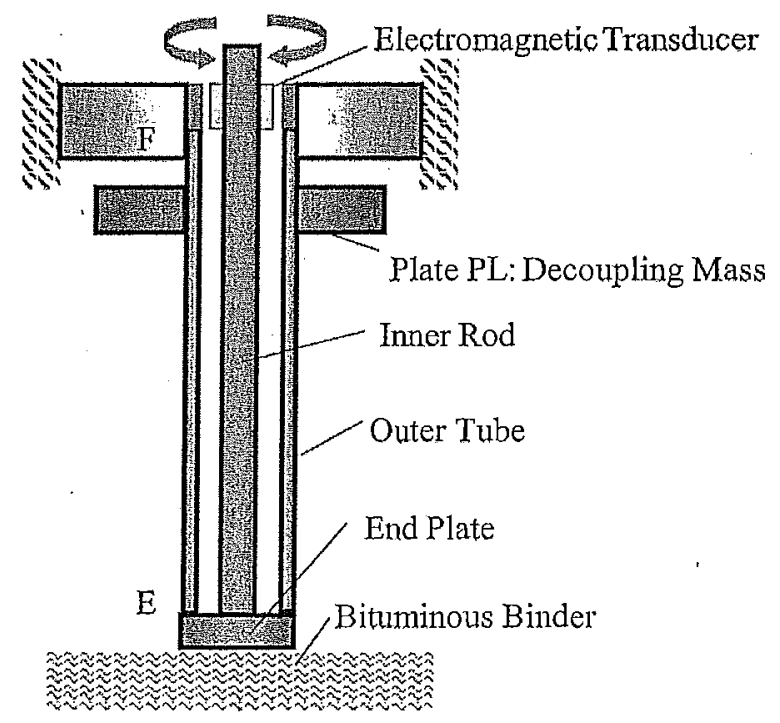

Fig. 1 - Scheme of the high-frequency torsional resonance rheometer (HFTR).

\begin{tabular}{|l|l|}
\hline \multicolumn{2}{|c|}{ Table 1-HTFR specifications } \\
\hline Frequency range & $1 \mathrm{kHz}$ to $60 \mathrm{kHz}$ \\
\hline $\begin{array}{l}\text { Stability of resonance } \\
\text { frequency }\end{array}$ & $10^{-2} \mathrm{~Hz}$ at $10 \mathrm{kHz}$ \\
\hline Sensor amplitude & Less than 1 micrometer \\
\hline Temperature range & -50 to $300^{\circ} \mathrm{C}$ \\
\hline
\end{tabular}

end $E$ of the tube where it joins the internal rod is solidly closed with an end plate. With an electromagnetic transducer, fixed at the free end $F$ of the internal rod, the system is forced to perform high frequency vibrations of very low amplitude at one of its torsional eigenmodes. The frequency $(5.4 \mathrm{kHz}$ in the present case) is stabilized within $0.01 \mathrm{~Hz}$ with the help of a phase-locked loop fixing the phase between the applied torque and the measured angle of rotation. Further details including those of the electronic control circuitry can be found in [1].

\subsection{Measurement principle}

Resonance frequency, $f$, corresponds to a phase angle of $90^{\circ}$. The damping $(\varepsilon)$ is proportional to the frequency difference $d f_{\alpha}$ of the frequencies $f_{-\alpha}$ and $f_{i \alpha}$ at two values $90^{\circ} \pm \alpha$ of the phase angle in the vicinity of resonance (Fig. 2):

$\mathrm{df}_{\alpha}=\mathrm{f}_{+\alpha}-\mathrm{f}_{-\alpha}$

$f=\left(f_{-\alpha}+f_{+\alpha}\right) / 2$

When the end plate is placed on the surface of the

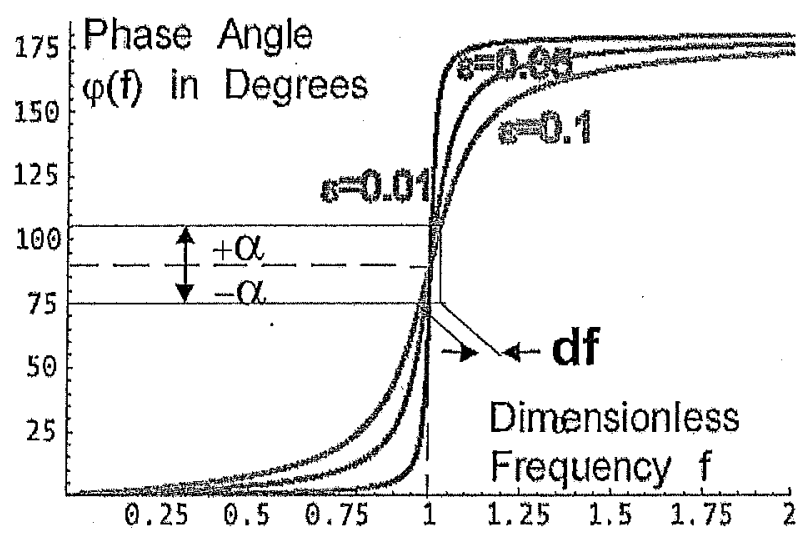

Fig. 2 - Phase spectrum.

viscoelastic bitumen, only a boundary layer of the binder in the immediate vicinity of the contact surface participates in the motion, provided that the frequency is sufficiently high. Nonetheless, the measured resonance frequency and the damping will change in comparison to similar measurements taken in air. Shear storage and loss moduli of the bituminous binder at driving frequency follow from the changes in $\mathrm{df}_{\alpha}$ due to interaction with the viscoelastic medium.

In Ref. [2] similar experiments were performed with the HTFR embedded in an asphaltic plug joint material. In the current experiment the rheometer is placed at a controlled depth of approximately 7.4-mm (cf. Fig. 6).

\section{MATERIALS AND TEST PROTOCOL}

Two different types of straight-1un bitumen have been used for this experiment with different penetration grade: $50 / 70,180 / 220$. The results of penetration tests at $25^{\circ} \mathrm{C}$ and 
ring and ball softening point tests and viscosity for each binder are presented in Table 2. Since aging and the rheological properties of bitumen are highly dependent on temperature and exposure to heat, an attempt was made to control the exposure time and temperature of the samples.

Before placing the end plate of the HTFR on the surface of the bitumen film, the values in air (indicated by subscript A) of resonance frequency $f_{A}$ (phase angle $90^{\circ}$ ) and frequency differences $\mathrm{df}_{\alpha A}$ for phase angles $90 \pm \alpha$ (in the present case $\alpha=22.5^{\circ}$ ) at varying temperatures are measured (cf. Fig, 3). In addition, these air values were periodically re-checked in order to verify that the rheometer is functioning properly. Temperature has a significant effect on the internal readings of the rheometer, therefore in order to record the changes in the binder only, the air values at relevant temperatures (in this case $90^{\circ} \mathrm{C}, 110^{\circ} \mathrm{C}$ and $135^{\circ} \mathrm{C}$ ) have to be subtracted. At these test temperatures the scatter

\begin{tabular}{|c|c|c|c|}
\hline \multicolumn{4}{|c|}{$\begin{array}{c}\text { Table } 2 \text { - Unaged penetration, softening point and } \\
\text { viscosity data }\end{array}$} \\
\hline Binder & $\begin{array}{l}\text { Needle } \\
\text { Penetration at } \\
25^{\circ} \mathrm{C}[0.1 \mathrm{~mm}]\end{array}$ & $\begin{array}{l}\text { Ring and ball } \\
\text { softening point } \\
{\left[{ }^{\circ} \mathrm{C}\right]}\end{array}$ & $\begin{array}{l}\text { Viscosity } \\
\text { at } 60^{\circ} \mathrm{C} \text { [Pa.s. }\end{array}$ \\
\hline $50 / 70$ & 74 & 48.8 & 415.0 \\
\hline $180 / 220$ & 168 & 43.2 & 50.1 \\
\hline
\end{tabular}

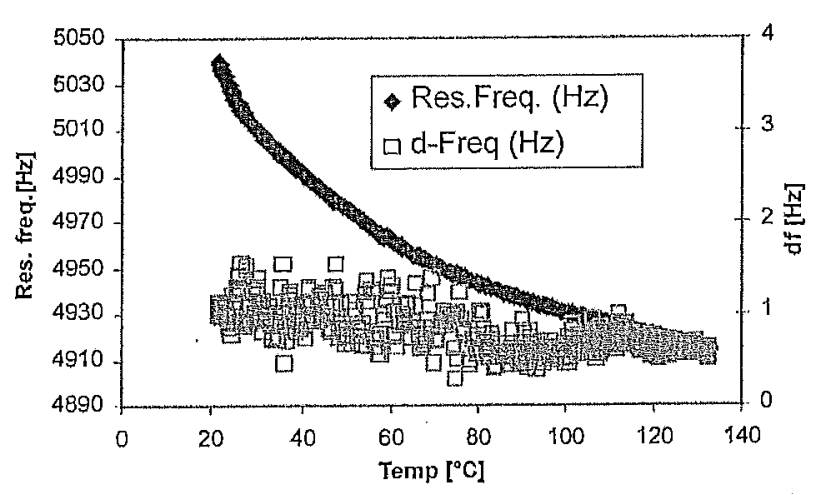

Fig. 3 - HTFR readings $f_{A}, \mathrm{df}_{\alpha A}$ in air at various temperatures.

of $\mathrm{df}$ is comparatively small.

Subsequently, the values on bitumen (indicated by subscript $B$ ) of resonance frequency $f_{B}$ and frequency differences $\mathrm{df}_{\alpha \mathrm{B}}$ are measured continuously. In the present case 7 measurements were taken every minute resulting in 420 measurements per hour.

References [3] and [4] were used as a guideline for sample preparation and testing. Test samples were placed on a TFOT pan and placed on a TFOT pan holder. The rheometer was supported by a specially designed support system on the TFOT pan holder, Figs. 4 and 5 show the rheometer during a test.

A $50 \mathrm{~g}$ sample of the bitumen being tested was cut out of the bitumen in the container and placed on a TFOT testing pan. The binder was warmed for one-half hour in the oven at test temperature in order to flatten in the pan. Thereafter the pan was placed on one of the TFOT shelves and the rheometer was lowered onto the

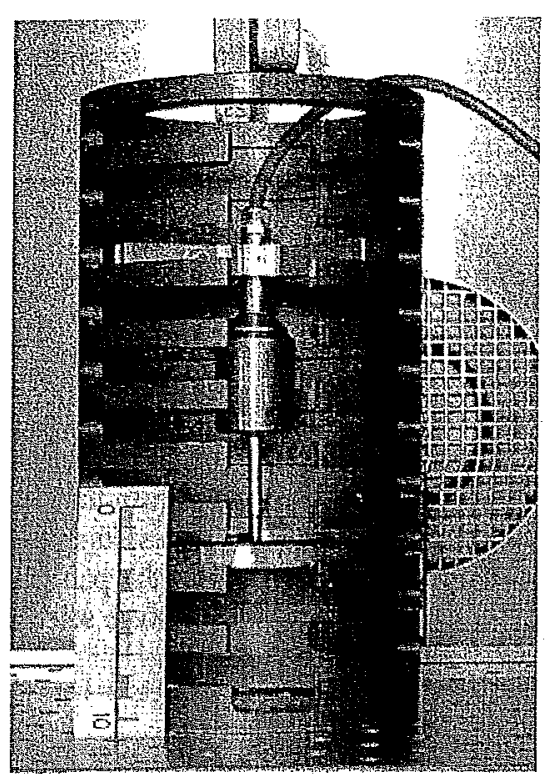

Fig. 4 - HTFR during a test.

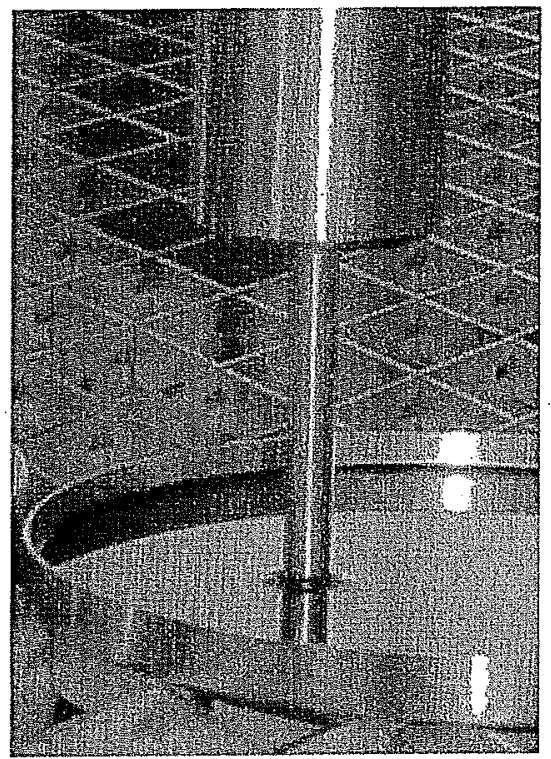

Fig. 5 - Tip of HTFR rod during a test.

bitumen. The distance between the end of the HTFR and the bottom of the pan (h in Fig. 6) was controlled with a two-gage: This is important since the amount of penetration depth of the tip of the HTFR into the material influences the amount of bitumen engaged in the test and therefore the readings of the rheometer. Using the Boundary Layer Theory [5], and the solution for a rotating disk the boundary layer for each test temperature was estimated (Table 3 ). It was assumed that the

\begin{tabular}{|c|c|c|c|c|c|c|c|c|}
\hline \multicolumn{9}{|c|}{$\begin{array}{l}\text { Table } 3 \text { - Result of boundary layer thickness estimate with } \eta=\text { dynamic viscosity; } \\
\rho=\text { density; } f=\text { frequency; } \omega=\text { allgular frequency }=2 \pi \mathrm{f} ; \delta_{90}=\text { Thickness of } \\
\text { boundary layer with fluid at } 60^{\circ} \mathrm{C} ; \delta_{110}=\text { Thickness of boullary layer with fluid } \\
\text { at } 110^{\circ} \mathrm{C} ; \delta_{135}=\text { Thickness of boundary layer with fluid at } 135^{\circ} \mathrm{C}\end{array}$} \\
\hline \multirow[t]{2}{*}{ Material } & $\eta$ & $\eta$ & $\eta$ & \multirow{2}{*}{$\begin{array}{c}\rho \\
{\left[\mathrm{g} / \mathrm{cm}^{3}\right]}\end{array}$} & \multirow{2}{*}{$\begin{array}{c}\omega \\
{[\mathrm{Hz}]}\end{array}$} & \multirow{2}{*}{$\begin{array}{c}\delta_{90} \\
{[\mathrm{~mm}]}\end{array}$} & \multirow{2}{*}{$\begin{array}{c}\delta_{1,10} \\
{[\mathrm{~mm}]}\end{array}$} & \multirow{2}{*}{$\begin{array}{c}\delta_{135} \\
{[\mathrm{~mm}]}\end{array}$} \\
\hline & $\begin{array}{l}90^{\circ} \mathrm{C} \\
{[\text { Pas }]}\end{array}$ & $\begin{array}{l}110^{\circ} \mathrm{C} \\
{[\mathrm{Pas}]}\end{array}$ & $\begin{array}{l}135^{\circ} \mathrm{C} \\
{[\text { Pas] }}\end{array}$ & & & & & \\
\hline $50 / 70$ & 22 & 3 & 0.28 & 1.028 & 31416 & 1.2 & 0.4 & 0.1 \\
\hline $180 / 220$ & 5 & 0.2 & 0.18 & 1.023 & 31416 & 0.6 & 0.1 & 0.1 \\
\hline
\end{tabular}




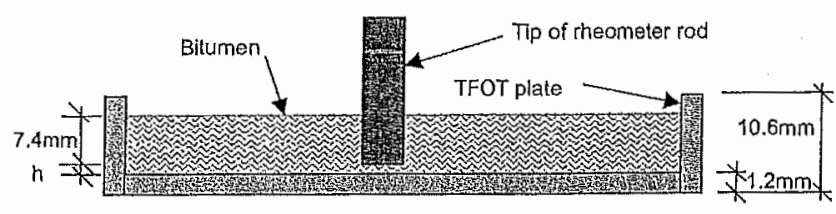

Fig. 6 - Scherne of the HTFR dipped into the bitumen on the TFOT plate.

dynamic viscosity remains constant during the test and the rheometer tip radius is much larger than the boundary layer. As a result of the estimated boundary layer thickness calculated and shown in Table 3 , a distance of $\mathrm{h}=2 \mathrm{~mm}$ from the bottom of the pan was determined to give reproducible results minimizing any interference resulting from the bottom of the pan (Fig. 6). Test temperatures of $90^{\circ} \mathrm{C}, 110^{\circ} \mathrm{C}$ and $135^{\circ} \mathrm{C}$ were selected in order to cover at least the range specified in [3].

\section{DISCUSSION OF RESULTS}

Aging of bituminous mixtures in the field occurs over time due to exposure to air and climatic loading, specifically heat. In [4] aging of a polymer modified asphaltic plug joint was monitored in situ for three years. The results indicated that at working temperatures $\left(-10^{\circ} \mathrm{C}\right.$ to $\left.50^{\circ} \mathrm{C}\right)$ both $\mathrm{df}$ and fincreased.

Figs, 7 and 8 show the fluctuations of resonance frequency (phase angle of $90^{\circ}$ ) $f_{B}$ and $d f_{\alpha B}$ while the HTFR is dipped into the bitumen at a constant temperature of $90^{\circ} \mathrm{C}, 110^{\circ} \mathrm{C}$ and $135^{\circ} \mathrm{C}$ for approximately a 24 hour periods. These conditioning temperatures and time showed that the resonance frequency has a tendency to increase however this increase is small compared to the stability of resonance frequency (Table 1), while $\mathrm{df}_{\mathrm{aB}}$, after adjustment for air values (Fig. 3), increase about $4.6 \%\left(90^{\circ} \mathrm{C}\right)$ and $4.8 \%\left(110^{\circ} \mathrm{C}\right)$ for Bitumen $50 / 70$ and $8.2 \%\left(110^{\circ} \mathrm{C}\right)$ and $26 \%\left(135^{\circ} \mathrm{C}\right)$ for Bitumen $180 / 220$. However in absolute terms the rate of increase for various materials and temperatures is similar as seen in Fig. 7. It was established in [4] that the measured values of resonance frequency, $f_{B}$, are proportional to the elastic part of the complex modulus. It was also explained that the frequency
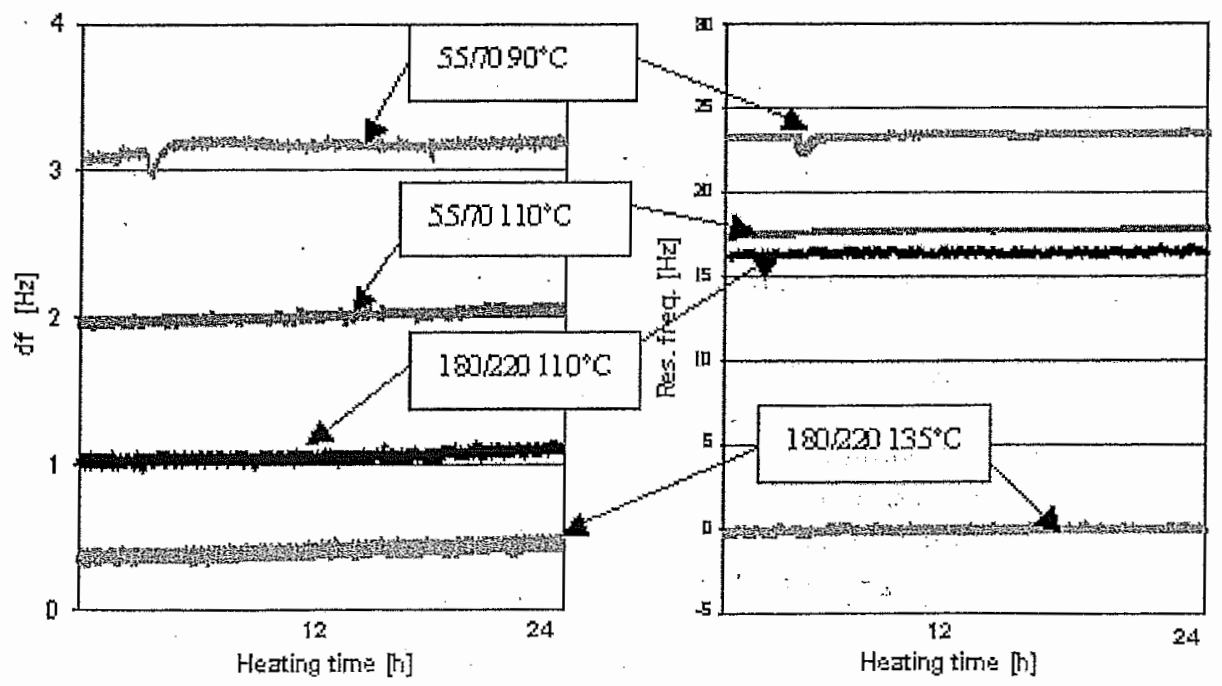

Fig. 7 - Changes in frequency difference $\mathrm{df}_{a, \mathrm{~B}}$ for Bitumens $50 / 70$ and $180 / 220$ conditioned for 24 hours.
Fig. 8 - Change in resonance frequency $\mathrm{f}_{B}$ for Bitumens $50 / 70$ and $180 / 220$ conditioned for 24 hours. difference, $\mathrm{df}_{\mathrm{aB}}$, is proportional to the viscous part of the complex modulus. Therefore, Figs. 7 and 8 suggest that during a 24 hour conditioning time of a 50/70 and 180/220 straightrun bitumen the viscous part has significantly increased whereas the elastic part of the complex modulus has a tendency to increase a small amount and the rate of increase of the elastic component appears to become smaller during the heating process.

Furthermore, measurement uncertainties arise in this study since the penetration depth of the rheometer tip into the material cannot be precisely controlled.

\section{CONCLUSIONS AND FURTHER WORK}

This ongoing study has pointed out that as a result of high temperature conditioning the top layer of bituminous binders go through a significant increase in damping characteristics. Elastic characteristics quantified by resonance frequency increase however not significantly and conditioning time plays a direct role in this change.

The HFTR appears to be a promising tool to characterize the mechanical effects of aging, which occurs in the top layer up to an unknown depth, without the need for mixing and homogenizing.

Similar studies using a Pressurized Aging Vessel (PAV), as well as low temperature oven tests are planned. Furthermore the effects of increasing/decreasing the distance between the tip of rheometer and bottom of pan will be studied. Polymer modified binders will also be studied.

\section{REFERENCES}

[1] Goodbread, J., Sayir, M., Häusler, K. and Dual, J., "Method and device for measuring the characteristics of an oscillating system'; US Patent No. 5,837,885, European Patent No. 0749570, 1998.

[2] Sayir, M.B., Hochuli, A.\& Partl, M.N., 'Measuring the complex viscosity of bitumen in the $\mathrm{kHz}$ range with a new resonance rheometer', Workshop Briefing, Euro-Bitume Workshop 99 on Performance Related Properties for Bituminous Binders, 3-6 May 1999 Luxembourg, Paper No. 106, 1999.

[3] AASHTO Standard Practice for Accelerated Aging of Asphalt Binder Using a Pressurized Aging Vessel (PAV), PP1-98.

[4] EN 12594, 'Bitumen and bituminous binders - Preparation of test samples', December 1999.

[5] Schlichting, H., 'Boundary Layer Theory' (McGrawHill, $7^{\text {th }}$ edition, 1979).

[6] Poulikakos, L.D., Sayir, M.B. and Partl, M.N., 'Long term field characterization of polymer bitumen using a new torsional dynamic resonance rheometer', Proceedings of the fourth European Symposium on Perfornance of Bituminous and Hydraulic materials in Pavements, BITMAT 4, Nottingham, UK, 1112 April 2002 